\title{
Evolução do Direito Social Brasileiro (*)
}

\author{
A. F. Cesarino Júnior \\ Professor das Faculdade's de Di- \\ reito e de Ciências Econômicas \\ da Universidade de São P'aulo.
}

1 - 0 estudo histórico de um direito nacional é, segundo penso, o meio mais concreto para apreender seus caracteres fundamentais. Era com razão que o grande $O r$ tolan dizia: "Todo historiador deveria ser jurisconsulto e todo jurisconsulto deveria ser historiador".

Com efeito, é sómente vendo se desenvolverem as instituições juridicas de um país, mesmo num dominio tão restrito como o nosso, que se poderá distinguir as correntes fundamentais que o animam, as razões de ser de suas disposições mais importantes, suas causas e seus efeitos, assim como os vinculos que o aproximam, seja dos outros ramos de direito nacional, seja à inspiraçâo mesma do direito comparado.

2 - Isto posto, apliquemos este metodo historico ao Direito Social Brasileiro. Mas, antes de começar, é preciso, de acôrdo com o sábio conselho de um celebre escritor, definir os termos. Eis porque vamos já dizer o que entendermos por Direito Social. Para nós, o Direito Social é o "sistema de principios e normas juridicas imperativas que, tendo em vista o bem comum, ajudam a satisfazer às necessidades vitais próprias e de suas famílias aos individuos para tanto dependentes do produto de seu tra-

(*) Tradução de conferência pronunciada em alemão, na Universidade de Heidelberg, em julho de 1952. 
balho". E como chamamos a êsses individuos economicamente fracos, de hipossuficientes, poderiamos dizer, em resumo, que o Direito Social é em síntese, "sistema jurídico de proteção aos hipossuficientes". Esta proteção póde ser alcançada, ou pela união dos hipossuficientes que dessa forma se tornam, primeiro fisicamente e depois politicamente mais fortes, o que é uma forma de proteção derivada deles mesmos, isto é, uma auto-proteção; ou pela intervenção do Estado, e então se trata de uma proteção vinda de outrem, isto é, de uma hetero-proteção. A primeira, que resulta da seus sindicatos (sindicatos gatue o regimen fascista tinha reunido a seus adversarios, os sindicatos patronais, em uma entidade unica, a corporação) denominamos, por este motivo, o objeto do Direito Corporativo.

Quanto à segunda, é necessario distinguir: com efeito, a proteção do Estado pode ser dirigida de uma maneira toda particular, verdadeiramente especifica, aos trabalhadores subordinados, isto é, aos operarios e aos empregados, e teremos o que denominamos o Direito do Trabalho; por outra forma pode ter em vista, genéricamente, todos os hipossuficientes, abstraindo-se de sua condição de trabalhadores ou não, e eis o que denominamos Direito Assistencial. Entretanto, isto não basta. Existem casos, tais os seguros sociais, em certos paises, como no Brasil, por exemplo, nos quais intervêm conjuntamente para realizarem a proteção, o Estado, o patrão e o operário ou o empregado. E' evidente que nesses casos existe uma combinação de auto-proteção e de heteroproteção, o que nós chamamos de Direito Previdencial.

Tudo isto é para nós Direito Social Restrito, pois que, na verdade, existe tambem lim Direito Social Generico, que será a adaptação da forma juridica à realidade social, como quer Radbruch. Este compreende tambem o Direito Economico, que não se ocupa das relações entrc os hipossuficientes e os economicamente fortes, que cha- 
mamos de autosuficientes, como o Direito Social Restrito, mas das relações entre alguns autossuficientes e outros economicamente mais fortes que êles e que por esse motivo denominamos "hipersuficientes". E' portanto a luta pelo dominio economico: os trusts, carteis, dumpings, etc. Vê-se, portanto, que existe uma hipossuficiencia absoluta, isto é, a situação do individuo que depende do produto do seu trabalho para viver e manter sua familia e uma "hipossuficiencia" relativa, ou seja, a situação de uma pessoa economicamente forte perante outra economicamente mais forte do que ela. Cada um desses Direitos, o Direito Social Restrito, ou o Direito Social, simplesmente, e o Direito Economico, obteve sua autonomia cientifica. Neste estudo cogitaremos sòmente do primeiro, cuja autonomia é confirmada pelo fato de que possue numerosas normas proprias, principios informativos próprios e método proprio, isto é, o método sociológico ou construtivo. Tambem sustentamos que o Direito Social possue institutos juridicos verdadeiramente tipicos, tais comc o contrato coletivo de trabalho e a sentença coletiva de trabalho. Mas, vamos além, pois admitimos ainda que o Di. reito Social nos traz um novo conceito juridico de pessoa, seja de pessoa fisica, seja de pessoa juridica. Com efeito, quanto à pessoa fisica, é preciso compreender que a proteção do hipossuficiente, dado o carater imperativo de suas normas, transforma o trabalhador subordinado a um patrão em uma pessoa juridicamente incapaz, se bem seja uma incapacidade relativa, isto é, restrita a determinados atos (aqueles que se relacionam com o contrato de trabalho) ou à maneira de os realizar. Ve-se, assim, que a capacidade juridica tem, no Direito Social, um sentido mais restrito do que em Direito Civil, si bem que a menoridade neste seja levada mais longe que em Direito Social (no Brasil, 21 anos e 18 anos respectivamente). Por seu lado, o Direito Social fez surgir duas novas pessoas juridicas: a empresa e a autarquia. Efetivamente, a empresa, mesmo quando pertença à uma pessoa física, 
dela se distingue sob o ponto de vista contabil, fiscal e em Direito Social tambem do ponto de vista juridico, O principio de continuidade do contrato de trabalho, que em casos de modificações substanciais ou formais na propriedade da empresa (sucessão "inter-vivos" ou "mortis-causa", locação, concordata) assegura aos empregados o poder de fazer valer contra o novo proprietário os direitos adquiridos e o dever de cumprir em beneficio deste as obrigações assumidas com o antigo proprietario, na realidade parte do fato de que o verdadeiro empregador é, não a pessoa fisica ou juridica do proprietário da empresa, mas justamente esta, à qual doravante, como titular de direitos e obrigações, não se poderá mais, em boa doutrina, negar os caracteres de pessoa juridica. Da mesma forma, o sindicato, sendo uma sociedade á qual o Estado, para lhe reconhecer personalidade juridica faz exigencias especiais e ao qual, em troca, cede uma parts de seus atributos, de seu "jus imperii", o poder normativo (isto é, o direito de estipular contratos coletivos de trabalho, obrigatórios para toda a calegoria) e o poder tributário (isto é, poder de impor contribuições aos membros da categoria, mesmo quando não pertencentes ao Sindicato na qualidade de socios e que no Brasil se chamam imposto sindical) não é evidentemente mais uma pessoa juridica de direito privado, como as associações ou fundações ou as sociedades comerciais. Mas não é tambem, verdadeiramente, uma pessoa juridica de direito publico, porquanto não possue originariamente e sim por delegação o "jus imperii", que caracteriza as verdadeiras pessoas de direito publico. É portanto, algo de novo, isto é, uma pessoa juridica de Direito Social, que nós chamamos de auturquia. Mas é necessario extender essas considerações alem, tal sua importancia. Existem normas e instituiçõcs de Direito Social que uma analise cuidadosa reconhece como diferentes, seja do Direito Privado, seja do Direio Publico: é preciso situá-las em um "tertium genus": a 
Direito Social. É portanto necessario completar a divisão do Direito dada por Ulpiano:"... hujus studii tres sunt positiones: publicum, privatum et sociale".

Eis, portanto, o que é para nós o Direito Social, do qual iremos descrever, em largos traços, a evolução no Brasil.

É preciso acentuar ainda que iremos abordar o Direito Social, ou melhor, sua evolução, a partir do momento. em que começou a existir propriamente um Direito Social,. isto é, após a revolução industrial, da qual podemos sentir os primeiros efeitos no dominio social no inicio do século. XIX.

3 - claro que é preciso estabelecer divisões na longa evolução do Direito Social Brasileiro, do Seculo: XIX até nossos dias. E para o fazer convem primeiramente fixar um critério.

Para nós o melhor critério será aquele que resulte do' exame das modificações sofridas pela orientação politica da legislação referente às instituições fundamentais. Com efeito, cada direito nacional ostenta, em seu conjunto, a impressão do regime politico do qual emana, o que levou um nosso compatriota, o ilustre professor Alipio Silveira, a sustentar a tese da interpretação juridica variavel com o regimen politico. Para o demonstrar, basta encarar, comı exemplo, o sindicato: nos paises onde o regimem politico segue uma orientação mais liberal, existe a mais ampla liberdade sindical, sobretudo sob os aspectos da pluralidade e da autonomia. Pelo contrario, onde se afirma o caráter autoritario do poder, ou o sindicato desaparece completamente ou se apresenta revestido dos caracteristicos da unidade sindical e de seu controle pelo Estado. Assim como o sindicato, outra instituição do qual' é derivado, o contrato coletivo de trabalho, sofre a influencia do sistema politico. Onde existem sindicatos livres e poderosos, os contratos coletivos desempenham: 
um papel tão importante que as leis sociais não têm necessidade de descer a minucias, como vemos, por exemplo, na atual legislação brasileira. Outra instituição de Direito Social poderia nos auxiliar na demonstração de nossa tése: é o contrato individual de trabalho. Assin no regimen nazista a Gesetz zur Ordnung der Nationalen Arbeit, isto é, a lei nacional alemã sobre o trabalho considerava o empregador como o chefe (der Fuhrer) da comunidade de empresa, (Betriebsgemeinschaft) e os operarios e empregados como sua escolta (Gefolgschaft), o que levou certos autores a considerar o contrato de tr:xbalho como um simples contrato de inserção na empresa, (Betriebseingliederung) deixando o pessoal em um verdadeiro status subjectionis, que somente terminava com a despedida (Betriebsausgliederug) o que negava, claramente, todo caráter contratual à relação de trabalho.

O testemunho mais chocante desta oposição nos foi dado por nosso caro colega Mario Deveali, antigo professor na Universidade de Roma e atualmente em La Plata, Argentina. Ele, que em seu livro II Rapporto di lavoro, sustentou face ao direito italiano a tése estatutária, ou por outras palavras, anticontratualista, aderiu alguns anos mais tarde à tése contratualista, que reconhece, em artigo publicado em sua revista "Derecho del Trabajo", como a única doutrina compativel com um regimen de liberdade.

Acreditamos que esta ligeira incursão no domínio do Direito comparado seja suficiente para nos autorisar a delinear a evolução do Direito Social Brasileiro por meì) das modificações sobrevindas especialmente no Direito Sindical, no curso das numerosas vicissitudes da vida nolitica do Brasil. É assim que após algumas palavras sobre o periodo que podemos com justiça chamar de "prehi:tórico" (1.500 - 1.888), descrevemos brevemente o periodo capitalista (1.888 - 1.930), em que praticamenie não existem sindicatos no Brasil; o periodo socialista (1.930 - 1.934), no qual, ao contrário, eles se desenvol- 
vem de uma maneira verdadeiramente notavel, mas com caracteristica de unidade e controle pelo Estado; o periodo social - democrático (1.934 - 1.937) durante o qual o desenvolvimento continua, mas sob um regime de pluralidade e autonomia sindical; o periodo corporativo (1.937 - 1.946), que nos conduz de volta $\dot{a}$ unidade sindical $e$ ao controle pelo Estado erigidos em principios constitucionais, e finalmente o periodo. . inominado (1.9/6 - 1952) que é o atual, em que persiste, a titulo precário, a organização sindical, sobre a base da unidade sindical e do controle pelo Estado, mas a Constituição em vigor, permite a adoção, pela lei, de principios inteiramente opostos àqueles e daí a denominação.

4 - Antes de termos o direito de falar sôbre a historia do Direito Social propriamente dito, é necessário, para sermos completos, abordar o estudo sumarissimo do periodo prehistorico, desde a descoberta do Brasil em 1500 até o aparecimento do movimento abolicionista, que encerrou em nosso país o regimen da escravidão.

Com relação a este periodo, poucas coisas interessantes existem para serem relatadas, não sómente pror causa da ausencia quasi completa do trabalho livre, mus ainda porque nessa ocasião a Historia do Brasil nada mais é do que um episódio da Historia de Portugal, o que escapa ao assunto deste estudo. É preciso acentuar que os escravos não sendo pessoas e sim coisas, óbviamente não podiam possuir direitos e que o trabalho livre, quasi inexistente, era regularmentado pelas leis portuguesas, notadamente pelas conhecidas Ordenações do Reino. Quando aos sindicatos, a bem dizer não existiam, porquanto o trabalho ainda se encontrava organizado em corporações de artes e oficios, sistema que sómente foi abolido pela Constituição Imperial de 1824. Portanto, não insistiremos sôbre o assunto. 
5 - Denominamos de prehistorico o periodo da evolução do Direito Social brasileiro compreendido entre a descoberta do Brasil em 1500 e as últimas medidas tomadas para a emancipação dos escravos. Delas as prí. meiras se iniciaram em 1828 pela Lei do Ventre Livre, segundo a qual os filhos de mãi escrava eram emancipados desde o nacimento. Êste movimento continuou com a supressão do tráfico de negros, a emancipação dos escravos sexagenários e se concluiu com a Lei Aurea, de 1888, que concedeu liberdade a todos os cativos. Paralelamente se iniciava a introdução de imigrantes no Brasil e, em consequencia, foram promulgadas as primeiras leis sôbre o trabalho livre, especialmente sobre o trabalho agricola. Êste fáto, que é caracteristico do Brasil e que chamamos a primeira inversão do Direito Social Brasileiro apresenta uma diferença notavel com o Direito Social europeu, motivada pela diversidade das con. dições economicas do Brasil e da Europa. Ao passo que na Europa, em virtude de seu desenvolvimento industrial, bem como em virtude da propria revolução industrial, que é o ponto de partida do verdadeiro Direito Social, êste dominio da ciência do direito se ocupa primeiro dos operarios, dos trabalhadores na industria, ou seja das cidades, donde seu urbanismo, no Brasil, que na ocasião só possuia agricultura, as leis, evidentemente, só poderiam proteger o trabalho rural, o unico existente. Portanto, na Europa, a proteção das leis sociais se desloca das cidades para o campo, ao passo que no Brasil o que ocorreu foi precisamente o inverso. $\mathrm{E}$ isto é de tal forma verdadeiro que os primeiros sindicatos de que se ocupou a lei brasileira foram os sindicatos rurais e a primeira manifestação legal dos tribunais do trabalho se encontra numa lei do Estado de São Paulo sôbre os tribunais rurais. Tamben a carteira de trabalho foi estabelecida, em primeiro lugar para o trabalho agricola. 
Estudemos agora o periodo que, iniciado em 1888, termina em 1930, compreendendo assim mais de um século. Ele se desenvolve sob duas formas de governo dissemelhantes, a Monarquia e a Republica, mas que do ponto de vista que nos interessa, não trouxeram mudanças de vulto, à situação juridica dos trabalhadores brasileiros.

Com efeito, a primeira, que se manifesta pela Constituição Imperial de 25 de Março de 1824, revista em 1831, não cogita das questões de trabalho, salvo para declarar dissolvidas as corporações de Artes e Oficios, com seus Chefes, Juizes e Escrivães. Durante todo o periodo em que esteve em vigôr, ou seja, até 1891, apenas encontramios as já citadas leis sobre os contratos de trabalho na agricultura e abolição da escravatura, definitivamente concedida em 1888. Este fato, da mais alta importancia na historia brasileira, produziu a queda da Monarquia e o exilio do grande Imperador D. Pedro II, que a França acolheu tão bem até a sua morte.

A Republica do regimen da Constituição de 24 de Fevereiro de 1891 pouco fez para a melhoria das condições dos trabalhadores brasileiros. Seu texto consagra apenas a liberdade de trabalho; e quanto à sua interpretação é bastante lembrar que se discutia sôbre a constitucionalidade de algumas leis sociais promulgadas no primeiro quarto do século XX. Foi necessário, por ocasião da reforma constitucional de 7 de Setembro de 1926, tornar explicita a competencia da União Federal para legislar sôbre trabalho. Isto não impediu que tivessemos algumas leis sôbre sindicatos, os quais, aliás, não se desenvolveram sob este regime; uma lei sôbre os acidentes do trabalho, embora primitiva, não abrangendo todos os trabalhadores e não prevendo a possibilidade da insolvencia do empregador; uma lei sôbre previdencia social dos ferroviários; uma outra sôbre a proteção do trabalho dos menores, regulada num código especial, etc. Mas, entretanto, chamo este periodo de periodo capitalista ou 
individualista, porque apezar do Brasil, em 1919 ter aderido à Organização Internacional do Trabalho, assinand,y e ratificando varias de suas convenções, não havia em nosso país uma mentalidade social bem definida. $\dot{E}$ bastante para disto ficarmos convencidos, lêr a conferencia sôbre a questão social, pronunciada em 1919 pelo maior dos brasileiros, RuY Barbosa. Falava-se mesmo ern 1930 haver um Presidente da Republica dito que a questão social era um caso de policia. Veridica ou não, a divulgação desta expressão permite bem compreender o espirito da época, no entanto tão proxima da nossa.

Foi sómente em 1930 que a questão social se impoz ao espirito dos homens públicos. E verdade que a industrialização do país, surgida com a primeira grande guerra, tomou' um desenvolvimento consideravel. Getulio VArGas, então candidato de um partido que, entretanto, se chamava Aliança Liberal, apresentou um programa verdadeiramente socialista. Vencido nas urnas, mas vencedor na revolução que se seguiu, sob sua ditadura cumpriu como chefe do governo provisorio o que havia prometido como candidato. Podemos dizer que foi nêsse momento que o direito social começou realmente a existir no Brasil.

5 - O Governo Provisório, instituido pelo movimento revolucionario de 1930, sistematizou a elaboraçâo de nossa legislação social. Inicialmente criou o Ministério do Trabalho, Indústria e Comércio. Seu primeiro Ministro LiNDOLFo Collor, obteve a colaboração de técnicos de valor em nossa disciplina, tais como o Prof. Oliveira Viana, a que se seguiram mais tarde Bandeira de Mello, Helro Lobo, Oscar Saraiva, Rego Monteiro, Costa Miranda e varios outros. Assim se iniciou a redação de numerosọs projetos, em boa hora convertidos em leis pelo governo revestido de poder ditatorial. Desta maneira se delineou o monumento, hoje importantissimo, do Direito Social Brasileiro. 
Hoje posuimos leis, quasi todas bem elaboradas, sôbre todos os assuntos, feitas após um estudo consciencioso das; leis estrangeiras, especialmente as dos paises latinos. Os sindicatos são estruturados por uma lei de 1931, com os caracteres da unidade sindical, neutralidade sindical e seu controle pelo Estado.

Com essa consagração legal se incrementa o interesse pela sindicalização e o numero de sindicatos se eleva rapidamente a dois mil. A lei sobre acidentes do trabalho é consideravelmente aperfeiçoada pela adoção de medidas para efetivar. em todos os casos, a indenização assegurada ao trabalhador. Toda vida operária é regulamentada com introdução da carteira profissional, da jornada máxima de trabalho, da proteção ao trabalho feminino e dos menores, do repouso semanal obrigatório, da proteção ao desemprego, aliás raro no Brasil, de dispensas indenizadas, de regulamentação das profissõeis, da extcnsâo do seguro social a todos os trabalhadores das empresas de serviços públicos e do comércio, do contrato coletivo de trabalho baseado na lei francesa de 1919, da organização de tribunais administrativos paritários para dirimir ou conciliar os dissidios individuais e coletivos de trabalho, etc.

Ha então uma acumulo de leis sociais, tão opostas ao individualismo do periodo anterior, que não temos. dúvida em designar esta fáse como periodo socialista, tanto mais que as leis são aplicadas com empenho pelo Ministério do Trabalho e pelo Conselho Nacional do Trabalho e a própria doutrina do Direito Social, ao mesmo tempo que a jurisprudência sobre o assunto fazem sua aparição no cenário jurídico brasileiro. Na mesma ocasião são criadas as cadeiras de Direito do Trabalho ou Legislação Social nas Universidades brasileiras.

6. O periodo discricionário do Govêrno, não podia, entretanto, pierpetuar-se. Depois da revolução paulista. 
de 1932, denominada revolução constitucionalista, realizou-se a eleição da Assembléia Nacional, que promulgou a. Constituição de 16 de Julho de 1934. Essa contituição) se inspira integralmente na Constituição Alemã de Weimar e organiza um regime social democrático, conservando, com algumas restrições, as leis sociais do periodus discricionário, cujos princípios figuram em um capítulo sôbre a ordem econômica e social.

E facil de se compreender que após a instalação do Parlamento a atividade legislativa deveria restringir-se, ao passo que, com a reaparição das idéias liberais, se tendia a restabelecer um regime de sindicatos plurimos e autonomos. Durante o periodo social democrático encontramos raras leis: sôbre as comissões de salário minimo, nova lei de indenizações por despedida, lei sôbre os seguros sociais para os operários, etc. A mais importante é a que creou uma instituição jurídica unica no mundo, isto é, a instituição da estabilidade. Por essa lei de 1935, nenhum trabalhador da indústria ou comércio que tenha trabalhado dez anos ou mais na mesma empresa, pode ser despedido a não ser que se prove ter ele cometido falta grave, o que será constatado por um processo regular. Esta instituição, que existe ainda hoje no Brasil, priva o empregador do direito de recisão teral do contrato de trabalho, mesmo que se prontifique a pagar perdas e danos, pois que é sómente com a autorização da Justiça do Trabalho que êle pode despedir seu empregado ou operario.

7 - Em 10 de novembro de 1937, um golpe de estado, perpetrado pelo próprio Presidente da República, lançou por terra o regime da Constituição de 1934 e erigiu, em seu lugar, um estado do tipo autoritário, de estrutura teoricamente corporativista. Voltamos, então, ao regime da unidade sindical e do controle do sindicato pelo Estado. O sindicato foi organizado de maneira fascista, dotado de poder normativo e de poder tributário, mediante a con- 
tribuição obrigatória de todos os membros da categoria ao respectivo sindicato, o que se denomina imposto sirrdical. É preciso acentuar a tentativa, inoperante na prática, de conciliar dois sistemas tão opostos como os da pluralidade e da unidade sindical. No Brasil esta anomalia perdura até hoje. Não se pode fundar imediatamente um sindicato. É preciso primeiro fundar o que se chama uma associação profissional que pleiteará, mais tarde, ao Ministro do Trabalho, seu reconhecimento como sindicato. Só então receberá o direito de representar sua categoria.

Evidentemente, logo quie o creador de nossa legislação social retomou o poder discricionário, este deveria retomar o seu desenvolvimento. Agora, os seguros sociais são extendidos a todos os trabalhadores, abstração feita, dos trabalhadores rurais, que por um fenômeno que chamamos de segunda inversão da legislação social brasileira, depois de serem os primeiros protegidos pela lei até 1930, são depois dessa data quasi que inteiramente deixados de lado. A Justiça do Trabalho se organiza completamente de forma judiciária e paritária, isto ẻ, com Juizes empregados, empregadores e representantes do Govêrno, tomando o caráter de permanência, com plenos poderes decisórios e de execução compulsória. Os sindicatos se desenvolvem, o que prepara a organização, corporativa do país, que apenas está delineada.

Visto o número já acabrunhante de leis trabalhistas, foram elas sistemàticamente reunidas em um código, denominado Consolidação das Leis do Trabalho. Essa consolidação, sob o ponto de vista da técnica legislativa, não é perfeita, nem completa, pois que não contem leis importantes como as referentes aos acidentes do trabalho Foi feita outra tentativa de codificação, dessa vez con relação às leis de assistência e de seguro social, cujos diversos institutos foram reunidos no Instituto dos Ser. viços Sociais do Brasil (ISSB). Infelizmente, esta unificação que viria corrigir os numerosos inconvenientes do 
sistema atual de multiplicidade das instituições de previdência social, cada uma delas com seus associados privativos, sua administração, seu regime de contribuições e de beneficios e seus numerosos funcionários, não foi posta em prática em virtude de novo golpe de estado, o de 29 de outubro de 1945, que afastou do poder o Presidente Getulio Vargas e que, em grande parte, foi uma consequência da vitória das Nações Unidas.

8 - A Assembléia Nacional, então eleita, manteve a Constituição ditatorial de 10 de novembro de 1937 até à promulgação de nova. O Presidente da República, também eleito nessa ocasião, conservou, no periodo transitório, o poder de expedir decretos-leis. Aproveitou-se êle: para decretar, de acôrdo com as tendências internacionais dominantes, o reconhecimento do direito de gréve, que a Constituição de 1937 havia proscrito. Esta lei, o. decreto-lei n. ${ }^{\circ} 9.070$, bateu todos os recordes de inconstitucionalidade; era incostitucional tendo-se em vista a Constituição de 1937, de que falamos e que estava em vigor no momento de sua publicação, pois que permite a gréve, que a Constituição de 1937 denominava um recurso antisocial; é ainda inconstitucional perante a nova constituição, promulgada em 18 de setembro de 1946, pois que esta reconhece expressamente o direito de gréve, que a lei sómente regulamentará e, entretanto o decreto-lei $\mathrm{n}^{\circ}{ }^{-}$ 9.070 proibe a gréve nas atividades que ela considera "fundamentais" e que são quasi todas as principais formas. de trabalho. Antes de interromper o trabalho é preciso que os trabalhadores nas atividades consideradas como "acessorias" procurem chegar com os empregadores, a um acôrdo obtido pelas próprias partes; em sua falta, pela mediação dos representantes do Ministério do Trabalho e em sua falta ainda por intermedio do Presidente do Tribunal Superior ou Regional do Trabalho, conforme a extensão do conflito. Si não se chegar a um acôrdo, sòmente então a greve será licita. Doutra forma os trabalhadores. 
terão rescindidos os seus contratos de trabalho sem nenhum direito às indenizações de antiguidade e pieáviso.

9 - A nova Constituição Federal, de 18 de Setembro de 1946, manteve a legislação social brasileira quasi que com os mesmos caracteristicos que tinha nos anteriores. Inovou sómente, sem falar na organização sindical, que já examinamos e na supressão dos aspectos corporativos creando novos benefícios para o trabalhador brasileiro, a saber: salário minimo para ele e para sua familia, ao passo que anteriormente o salário minimo era apenas individual; a participação dos trabalhadores nos lucros da empresa e o pagamento do salário nos dias de repouso (domingos e feriados civis e religiosos). Esta ultima regalia é a única que já está regulamentada pela lei ordinária e consequentemente concedida aos trabalhadores. O salario minimo familiar é ainda objeto de estudos do Ministério do Trabalho. Com referência à participação nos lucros existem em curso no Parlamento vários projetos de lei, mas a reação patronal é grande e não se pode esperar vê-la aprovada em curto prazo, pois que se fala mesmo de uma reforma constitucional para suprimi-la. Lamentamos o que se passa, pois estamos inteiramente convencido de que a participação dos trabalhadores nos Iucros da empresa é o único meio exequível de terminar com a luta de clases. Procura-se também, através de númerosos projectos em estudos no Parlamento brasileiro, aperfeiçoar a Justiça do Trabalho e codificar as várias leis sôbre seguros socias por meio de uma lei orgânica sôbre a previdência social.

10 - Até agora falamos apenas sôbre a legislaçào social brasileira, isto é, examinamos exclusivamente sua anatomia. Estareis certamente curiosos de saber como ela funciona, ou por outras palavras, desejareis conhecer 
também sua fisiologia. Procuraremos satisfazer-vos sôbre este assunto.

No que se refere aos sindicatos, dos quais tanto falamos em virtude da importância que lhes atribuimos no dominio de nossa matéria, infelizmente devemos apresentar uma impressão pessimista. Já dissemos que no Brasil não temos autonomia sidical. O controle do Govêrno sôbre os sindicatos é grande. Não sómente são subordinados ao Ministro do Trabalho que lhes atribue a representação legal da categoria, mas também suas diretórias e suas contas devem ser aprovadas por este Ministério, o qual, além disso, tem o direito de intervir à sua vontade em sua administração. Se se acrescentar a isto a constatação de que sendo tão numerosas e minuciosas as leis sociais brasileiras, pouco ha a fazer para os contratos coletivos de trabalho, se compreenderá facilmente que os sindicatos e os contratos coletivos no Brasil estão longe de ter a importância que desfrutam nos Estados Unidos da América, por exemplo. As greves, sôbre as quais já esboçamos a situação legal, são, consequentemente, pouco numerosas, si bem que recentemente tenha havido um surto relativo. A Justiça do Trabalho realiza um grande serviço, seja procurando disciplinar os dissidios coletivos, seja decidindo numerosas questões entre empregadores e empregados (este termo no Brasil compete tanto ao que se chama empregado, como operário) principalmente com relação às rescisões unilaterais do contrato de trabalho. Ela é prejudicada, todavia, por sua constituição paritária, que permite a leigos decidir questões de direito $e$ também pelos "reliquats" no processo, de sua antiga organização administrativa, si bem que hoje seja uma instituição integralmente judiciảria.

Ém matéria de direito do trabalho o que primeiramente chama a atenção, segundo os juristas estrangeirost é o instituto da estabilidade, isto é, a proibição, somente para o empregador, de rescindir vinilateralmente o con- 
trato de trabalho do dependente com mais de 10 anos de serviço à empresa. O empregado não pode ser despedido a não ser que a Justiça do Trabalho o declare culpado de uma das faltas estritamente previstas na lei. E o empregado estável também não pode deixar seu emprego, pelo menos de uma maneira valida para seu empregador, se não fizer ratificar sua demissão pelo Sindicato, ou na sua falta, por um agente do Ministério do Trabalho ou da Justiça do Trabalho. Este sistema é extraordinàriamente constrangedor para a empresa porque, além do absurdo da perpetuidade da relação jurídica (o contrato de trabalho não podendo ser rescindido unilateralmente pelo empregador sem justa causa, mesmo se estiver êle disposto a pagar as perdas e danos) ha o fato, várias vezes constatado, do empregado não cumprir devidamente os seus deveres, sem que o empregador possa forçá-lo a isso em virtude de sua estabilidade.

Parece, entretanto, dificil modificar esta situação, porquanto a estabilidade é assegurada péla Constituição e os empregados se esforçam em mantê-la. Sómente o empregado com menos de dez anos de serviço pode ser despedido mediante o pagamento do prévio aviso de um mês de salário e uma indenização de antiguidade de um mês de salário por ano de serviço ou fração igual ou superior a seis meses. Em matéria de salários temos também o salário minimo geral para todas as atividades profissionais e não por empresas, salvo raras exceções estabelecendo salários minimos profissionais para médicos, jornalistas, radialistas, etc.

Já dissemos que existem no Brasil numerosas instituições de previdência social. Na verdade, o seguro social no Brasil é mantido por um sistema de instituições, umas inter-profissionais, outras intra-profissionais ou por empresas. Assim temos os Institutos de Aposentadorias e Pensões para os trabalhadores do comércio, da indústria, dos bancos, dos transportes, do trabalho maritimo $\mathrm{e}$ as 
Caixas de Aposentadorias e Pensões para os empregados dos serviços públicos, ferroviários etc., estas organizadas tambem por grupos de empresas semelhantes.

Em virtude dos interesses creados, tem sido inuteis as tentativas de unificação de todas as instituições, que evidentemente tornam mais dificil e mais cara a previdência social no Brasil. Açrescente-se à essas dificuldades que o Govêrno não paga pontualmente a essas instituições, como deveria, as contribuições especiais que todavia cobra dos cidadãos: os institutos de previdência social são assim obrigados a elevar o preço da contribuição patronal e operária, o que atualmente representa cerca de $6 \%$ sôbre o salário mensal. Todavia esses instintos asseguram a aposentadoria, salvo para os ferroviarios, somente por invalidez, pensões e auxilios em caso de doença ou enfermidade. Os acidentes do trabalho são objeto de um seguro especial a cargo de empregador.

No que se refere à assistência, o Estado, além de manter numerosas organizações de proteção á saúde, á educação, etc. concede subvenções a instituições particulares de beneficiência, especialmente á Legião Brasileira de Assitência, dedicada á proteção da maternidade e da infância, bem como à Fundação da Casa Popular, destinada á construção de habitações para os trabalhadores. Entre estas ultimas seria justo citar as organizações creadas pelos patrões e por eles sustentadas e que são para a indústria o Serviço Nacional de Aprendizagem Industrial (SENAI) e o Serviço Social da Indústria (SESI) e para o comércio o Serviço Nacional de Aprendizagem Comercial (SENAC) e o Serviço Social do Comércio (SESC) que mantêm, làs expensas dos empregadores, escolas profissionais e primarias, hospitais e serviços medicos, serviços de abastecimento, de recreio, etc. Apesar disto ainda ha muito a fazer no Brasil neste setor, porquanto a pobreza $\dot{\beta}$ grande, sobretudo no norte do país. 
11 - A patologia do Direito Social, isto é, a jurisprudência, desempenhou, maugrado a juventude de nossa disciplina, um papel importante em seu aperfeiçoamento. Por deficiência de tempo não a iremos analizar com pormenores. Cremos que será bastante lembrar que ela no Brasil já firmou orientações que mais tarde passaram à legislação, como por exemplo com referência à aplicação do direito comum pela Justiça do Trabalho; sôbre a retroatividade de certas leis sociais, como as referentes à estabilidade; a aquisição antecipada da estabilidade no caso de despedida com o fito único de obstá-la; também o que se denomina "despedida indireta" ou a coação patronal para forçar o empregado a apresentar demissão; à soma de periodos de trabalho não continuos, etc. òbviamente esta jurisprudência é a do Tribunal Superior do Trabalho, de jurisdição nacional, do qual dependem, nas regiões, formadas de dois ou mais Estados (provincias), em número de oito no total, os Tribunais Regionais do Trabalho, por sua vez superiores aos Tribunais (Juntas) de Conciliação e Julgamento, nas Capitais ou grandes cidades e aos Juizes do Trabalho (que são os juizes dos próprios Tribunais comuns) nas outras. Nos Tribunais existem representantes dos empregadores e dos empregados, indicados por seus sindicatos de primeiro ou segundo gráu.

12 - O movimento doutrinário do Direito Social Brasileiro, no momento, é intensissimo. Começou ainda no periodo capitalista, com a obra de Evaristo de Moraes Apontamentos de Direito Operario, seguida de outras sôbre a questão social, como as de Viveiros de Castro e Sampaio Doria e comentários às leis sociais da época. Depois de 1930 numerosos trabalhos foram publicados, ou pelos técnicos do Ministério do Trabalho, sobretudo Oliveira Viana, Waldyr Niemeyer, Buys de Barros, Dorval de Lacerda, Evaristo de Morais Filho, Segadas Viana, atual Ministro do Trabalho, Arnaldo Sussekind, Oscar Saraiva, ou pelos es- 
tudiosos do Instituto de Direito Social, que fundamos en São Paulo, em 1939. Este Instituto realizou no Brasil uma grande obra no dominio do Direito Social, estudado por ele, seja em livros ou revistas. seja em Congressos Nacionais, reunidos com a colaboração dos Govêrnos do Brasil e do Estado de São Paulo e dos quais os anaes foram publicados em vários volumes. Ao Instituto pertencem nomes hoje muito conhecidos no Brasil como Rur de Azevedo Sodré, Aguinaldo Miranda Simões, Egon Felix Gottschalk, Freitas Marcondes, Luiz Mesquita, etc. Nós mesmo, tivemos a honra de escrever no Brasil a primeira sintese de nossa disciplina em nosso Direito Social Brasileiro, hoje em sua terceira edição. A este livro seguiram-se: nosso Direito Processual do Trabalho, Direito Brasileiro do Trabalho de Segadas, Sussekind e Lacerda e Comentários à Consolidação das Leis do Trabalho de Mozart Victor Russomano. No Brasil são publicadas várias revistas de Direito Social, como nossa Revista de Direito Social, Trabalho e Seguro Social, Revista do Tribunal Superior do Trabalho, Boletim do Ministério do Trabalho, Legislação do Trabalho e Revista do Trabalho. Também fundamos em São Paulo a Sociedade Internacional de Direito Social que foi elogiada recentemente no Primeiro Congresso Internacional de Direito do Trabalho reunido em Trieste em 1951.

13 - Isto posto, convem, à guisa de conclusão desta sintése do Direito Social Brasileiro, tentar esboçar-lhe as caracteristicas. Como se viu o Direito Social Brasileiro é de recente formação, sendo uma consequência do nosso desenvolvimento industrial concomitante e posterior à I Grande Guerra. É paternalista, pois inicialmente surgiu mais da outorga do Estado, que da luta da classe proletária em favôr do melhoramento de suas condições, estando as greves no Brasil muito longe de haverem tido a importância por elas apresentada noutros países europeus ou norte americanos. $\mathbf{E}$ quasi exclusivamente urbano, 
pois os trabalhadores rurais nem mesmo na letra da lei gozam ainda das regalias do seguro social ou da indenização de antiguidade, sòmente se lhes aplicando, no mais das vezes teòricamente, as normas sôbre salário mínimo, férias e acidentes do trabalho e estando completamente sem atuação a lei de sindicalização rural, pelo menos quanto aos trabalhadores. A formação do Direito Social Brasileira, maugrado as mudanças de orientação do legislador já referidas, encontrou seu modêlo principalmente na legislação social fascista, sem, porém, termos tido, ao mesmo tempo, equivalente utilização dos contra-. tos coletivos de trabalho. Significa isto que o nosso Direito Social é predominantemente ou melhor, quasi exclusivamente estatal. Isto não obstante é êle dos mais completos do mundo, como é fácil verificar através dos trabalhos comparativos da Organização Internacional do Tra-balho. Si, dêstes caracteristicos gerais passarmos ao exame dos aspectos parciais, deveremos repetir que o nosso Direito Sindical se baseia, na unidade e neutralidade sindicais e no contrôle dos sindicatos pelo Estado; que as greves são permitidas, embora regulamentadas e admitidos os contratos coletivos de trabalho e instituída a Justiça do Trabalho para conciliar e julgar os dissidios individuais e coletivos de trabalho, tendo quanto a êstes poder normativo. No Direito Previdencial encontramos a organização pluralistica e autarquica dos institutos de seguro social, que, mantidos pela triplice contribuição do Estado, do empregador e do empregado, concedem aos empregados todos os benefícios de seguro por morte, seguro-invalidez, seguro-doença, seguro-acidente do trabalho, seguro-maternidade e para os ferroviários seguro-velhice. No Direito do Trabalho encontramos a relação individual de trabalho regulada detidamente, com a garantia de um salário mínimo e de indenização de aviso-prévio e de antiguidade e o original instituto da estabilidade. Finalmente no Direito Assistencial encontramos a assistência 
aos desajustados realizada ou subvencionada pelo Estado e largamente praticada pelos empregadores da indústria e do comércio.

Vemos assim que ao Direito Social Brasileiro, já dotado de uma legislação assaz completa, de uma jurisprudência frutifera e bem orientada e de uma doutrina que se esforça (embora ainda esteja longe de consegui-lo) por acompanhar-lhe o desenvolvimento legislativo e aplicado por uma administração infelizmente ainda reduzida aos quadros urbanos, falta apenas um esforço no sentido de tornar efetiva esta aplicação, não sòmente nas cidades, mas também nos campos, para ser, o que deve ser, isto é, um eficiente instrumento de paz social, vale dizer, igualmente uma valiosa contribuição para a paz universal, que em grande proporção naquela se alicerça.

14 - Tivemos assim, um ligeiro esbôço da evolução do Direito Social Brasileiro.

Como se deve ter notado, esforçamo-nos por apresentar uma exposição honesta, procurando mostrar tudo o que temos de bom ou de mau, não excluindo mesmo, levado por um falso patriotismo, êste último aspecto. Não teriamos agóra, para concluir, senão que falar da repercussão econômica das leis sociais no Brasil. Isto seria, por si só, assunto para um outro estudo que, obviamente, não nos propomos fazer nêste momento. Diremos sòmente, em resumo, que as leis sociais brasileiras oneram a produção, do ponto de vista do custo da mão de obra, em cêrca de $49 \%$, conforme as últimas estimativas de nossos economistas. 